\title{
Re-dissolution of VN during Tempering in High Chromium Heat Resistant Martensitic Steel
}

\author{
Manabu TAMURA, Takahiro IIDA, ${ }^{1)}$ Hiroyasu KUSUYAMA, ${ }^{11}$ Kei SHINOZUKA and Hisao ESAKA \\ National Defense Academy, Hashirimizu, Yokosuka 239-8686 Japan, \\ 1) Graduate School of National Defense Academy,
} Hashirimizu, Yokosuka 239-8686 Japan.

(Received on May 15, 2003; accepted in final form on July 26, 2003)

\begin{abstract}
Precipitation behavior of $\mathrm{VN}$ during isothermal tempering at $740-800^{\circ} \mathrm{C}$ of $7 \% \mathrm{Cr}-0.4 \% \mathrm{~V}-0.09 \% \mathrm{~N}$ steel (\% denotes mass \%, hereinafter) has been studied. Initially, rapid softening takes place accompanied by the precipitation of $\mathrm{VN}$ and, after that, the quasi-steady state in a hardness $\mathrm{vs}$. tempering time diagram is continuing for a while. After the quasi-steady state, re-dissolution of VN particles rapidly occurs followed by final precipitation of VN. Just before the peak time of the re-dissolution of VN particles, both the temporal decrease in hardness and the temporal increase in the integral breadth of an X-ray diffraction peak take place. The similar precipitation phenomenon is confirmed in $0.14 \% \mathrm{C}-9 \% \mathrm{Cr}-1 \% \mathrm{Mo}-0.2 \% \mathrm{~V}-0.09 \% \mathrm{Nb}$ steel. In both steels the re-dissolution of $\mathrm{VN}$ or $\mathrm{NbC}$ (hereinafter $\mathrm{MX}$ ) accompanies the decomposition of martensite. The following reactions are suggested as a mechanism for the re-dissolution of $\mathrm{MX}$ type particles: local stresses induced by the recovery of martensite unlock the pinning of dislocations by the MX type particles and the consequent isolated particles, which become energetically unstable, are re-dissolving into the matrix.
\end{abstract}

KEY WORDS: precipitation; hardness; X-ray integral breadth; Nb; VN.

\section{Introduction}

Since early 1980's a basic idea of the addition of a small amount of the strong carbo-nitride formers to full-martensitic heat resistant steel has been proposed in order to improve both high temperature strength and toughness. ${ }^{1)}$ Extensive research on the application of the idea to the practical components has been made ${ }^{2)}$ and $9 \% \mathrm{Cr}-1 \% \mathrm{Mo}-$ $0.2 \% \mathrm{~V}-0.08 \% \mathrm{Nb}-0.04 \% \mathrm{~N}$ steel has been registered in ASTM as A213 T-91. The rupture strength of T-91 is kept high for a long duration as compared with that of a plain $9 \% \mathrm{Cr}-1 \%$ Mo steel. ${ }^{3)}$ In other words, the average slope of a relation between $\log$ (time to rupture) and $\log$ (stress) of T-91 is smaller than that of the plain $9 \% \mathrm{Cr}-1 \% \mathrm{Mo}$ steel. However, the time dependence of rupture strength of T-91 is relatively still larger than that of $\alpha$-iron which contains finely dispersed MX type particles. ${ }^{4,5)}$ Therefore, the reason for the large improvement in rupture strength of T-91 should not be discussed merely in terms of precipitation hardening but discussed as a result of interactions between MX type particles and dislocations in martensite. In this sense, it is very important to study precipitation behavior of MX not in a simple ferritic steel but in a martensitic steel.

The precipitation behavior of carbo-nitride of MX type in high strength steels has been studied since 1950's and the results are summarized else where. ${ }^{6,7)}$ However, if a steel contains more than one kind of carbo-nitride formers, the precipitation behavior is very complex. ${ }^{8)}$ Concerning heat resistant steel, Tamura et al. ${ }^{9)}$ have newly reported the unfamiliar precipitation behavior that $\mathrm{NbC}$ particles precipitated during normalizing have been temporally re-dissolved during the subsequent short time tempering processes. The mechanism of the behavior has not been clarified, but the phenomenon is clearly supported by chemical analyses and electron microscopic observations. It has been generally known that MX type particles are cohesive precipitate of nanometer size $\mathrm{e}^{2,10)}$ and their sizes are steady for a long time. $^{11,12)}$ However, the detailed precipitation behavior of MX type particles in martensitic steel has not been investigated satisfactorily, because the contrast of MX type particles in a transmission electron microscope is strongly interfered with the contrast due to dislocations in martensite.

Among several kinds of MX type precipitates VN has been also judged to be important for the purpose of maintaining high temperature strength for a long time. ${ }^{11)}$ However, since practical heat resistant steels precipitate not only VN but also several kinds of compounds, i.e. complex MX type precipitates, $\mathrm{M}_{23} \mathrm{C}_{6}$ and Laves phase, the precipitation behavior in the practical steels is rather complex. Therefore, in this study the precipitation behavior of $\mathrm{VN}$ has been studied experimentally using a high chromium martensitic steel, which is designed only VN can be precipitated in the matrix. The same phenomenon as observed in the $\mathrm{NbC}$ precipitating system ${ }^{9)}$ was also expected in the $\mathrm{VN}$ precipitating alloy system, but in the preliminary study we cannot reveal the same phenomenon in the VN system as found in the $\mathrm{NbC}$ system, i.e. the re-dissolution of $\mathrm{NbC}{ }^{9}$ ) Therefore, the precipitation behavior of $\mathrm{VN}$ during only tempering has been systematically studied and finally we have found the similar re-dissolution phenomenon in the 
VN system as observed in the $\mathrm{NbC}$ system. And, therefore, the precipitation behavior of $\mathrm{NbC}$ during only tempering has been also re-investigated.

\section{Experimental Procedure}

A $50 \mathrm{~kg}$ ingot was hot-rolled to $12 \mathrm{~mm}$ plate. The chemical composition of the experimental steel is $0.0032 \% \mathrm{C}-$ $0.15 \% \mathrm{Si}-0.51 \% \mathrm{Mn}-0.002 \% \mathrm{P}-0.001 \% \mathrm{~S}-7.2 \% \mathrm{Cr}-0.3 \% \mathrm{Mo}$ $-0.41 \% \mathrm{~V}-0.091 \% \mathrm{~N}$ and the balance is $\mathrm{Fe}$. The $\mathrm{Nb}$ content is less than $0.0005 \%$. The hot rolled plate was normalized at $1200^{\circ} \mathrm{C}$ followed by tempering at 740,780 and $800^{\circ} \mathrm{C}$ for maximum $500 \mathrm{~h}$. It was confirmed that neither any precipitate composed of $\mathrm{V}$ nor delta ferrite was observed after normalizing at $1200^{\circ} \mathrm{C} .{ }^{13)}$

A heat-treated specimen was dissolved in $6 \mathrm{~N}-\mathrm{HCl}$ solution and the residues were separated using a filter with $0.2 \mu \mathrm{m}$ pores. The dissolved $\mathrm{V}$ in the filtered solution is directly measured using an inductively coupled plasma atomic emission spectroscope (ICP). The detailed experimental procedure and the accuracy of the analyzing method are reported in the previous paper. ${ }^{13)}$ Vickers hardness number was determined under $10 \mathrm{~kg}$ load and optical microstructure and scanning electron microscopy were observed after etching using the Vilella's reagent. Integral breadth of a $\{110\}$ diffraction peak was also measured using $\mathrm{CuK} \alpha_{1}$ characteristic X-ray. An extracted carbon replica was observed using a transmission electron microscope of a field emission type (FE-TEM) operating at $200 \mathrm{kV}$ and the chemical compositions of some particles were analyzed using an energy dispersive spectroscope (EDS).

\section{Experimental Results}

\subsection{Dissolved V}

The measured values of the dissolved $\mathrm{V}$ in the matrix of the tempered state are shown in Fig. 1. The dissolved V decreases with increasing tempering time up to about $10 \mathrm{~h}$ and the decreasing rate is fast when tempering temperature is high. This decrease corresponds to the precipitation of $\mathrm{V}$ compound. After about $10 \mathrm{~h}$ tempering, the dissolved $\mathrm{V}$ has been kept roughly constant for a few 10's h independent of tempering time and temperature, which suggests that the precipitation of V-compound looks like to reach the equilibrated state after about $10 \mathrm{~h}$. At this stage, roughly speak-

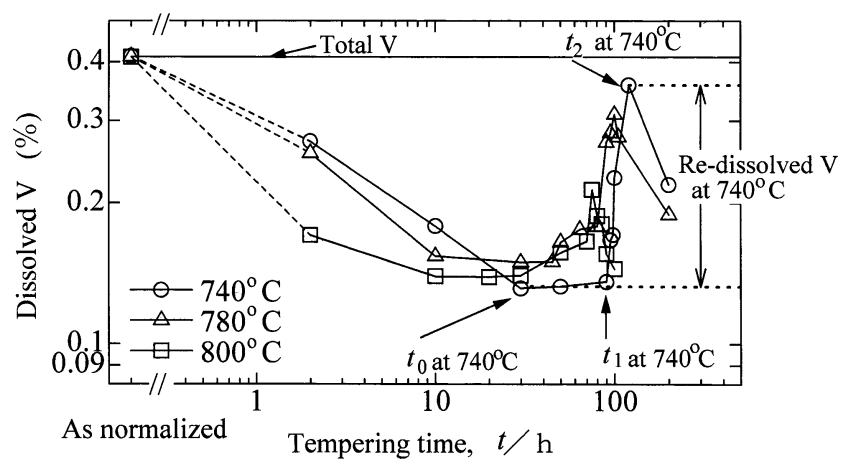

Fig. 1. Relation between dissolved $\mathrm{V}$ and tempering time. Symbols, $t_{0}, t_{1}$ and $t_{2}$, indicate the characteristic turning points of the folding line of $740^{\circ} \mathrm{C}$ and the definitions are shown in the text. ing, $0.15 \%$ of $\mathrm{V}$ is dissolved in the matrix and $0.26 \%$ of $\mathrm{V}$, i.e., (total $\mathrm{V}-\mathrm{V}$ in the matrix) $\approx 0.41 \%-0.15 \%=0.26 \%$ is in precipitates. However, the dissolved V unpredictably begins to increase and after reaching the peak value of the dissolved V, it begins to decrease again. In other words, it is clearly shown that a V-compound, which precipitates during tempering of several 10 's $\mathrm{h}$, is re-dissolving temporarily into the matrix and again a V-compound finally precipitates into the matrix.

Three kinds of characteristic time in Fig. 1, i.e. the reaching time to the apparent saturation of the V-compound precipitation, the beginning time of the re-dissolution and the peak time of the re-dissolution, are defined as $t_{0}, t_{1}$ and $t_{2}$, respectively, and they are indicated by arrows for the $740^{\circ} \mathrm{C}$ curve. These characteristic times are short when tempering temperature is high. It is also found from Fig. 1 that the amount of the re-dissolved $\mathrm{V}$ is large when tempering temperature is low.

\subsection{Hardness}

The results of Vickers hardness test of the tempered specimens are shown in Fig. 2. Hardness decreases roughly monotonically with increasing tempering time depending on the tempering temperature. However, for each temperature, a small depression in a hardness-tempering time diagram is observed after a plateau. These depressions are observed near the beginning time of the re-dissolution, $t_{1}$ which is defined in Fig. 1. The depression observed at $740^{\circ} \mathrm{C}$ is enlarged in the figure. The change in hardness number near the depression is about 10 to 20 at most, but it is confirmed that the change is obviously significant as compared with the scattering of the observed hardness values.

\subsection{Integral Breadth of a $\{110\}$ Diffraction Peak}

The change in integral breadth of a $\{110\}$ diffraction peak as a function of tempering time is shown in Fig. 3. The integral breadth depends on some metallurgical factors, for example the effective particle size defined by Stokes and Wilson $^{14)}$ and/or the local strain. ${ }^{15)}$ The integral breadth of the normalized state should be enlarged by the local strain due to martensite induced. The integral breadth should be

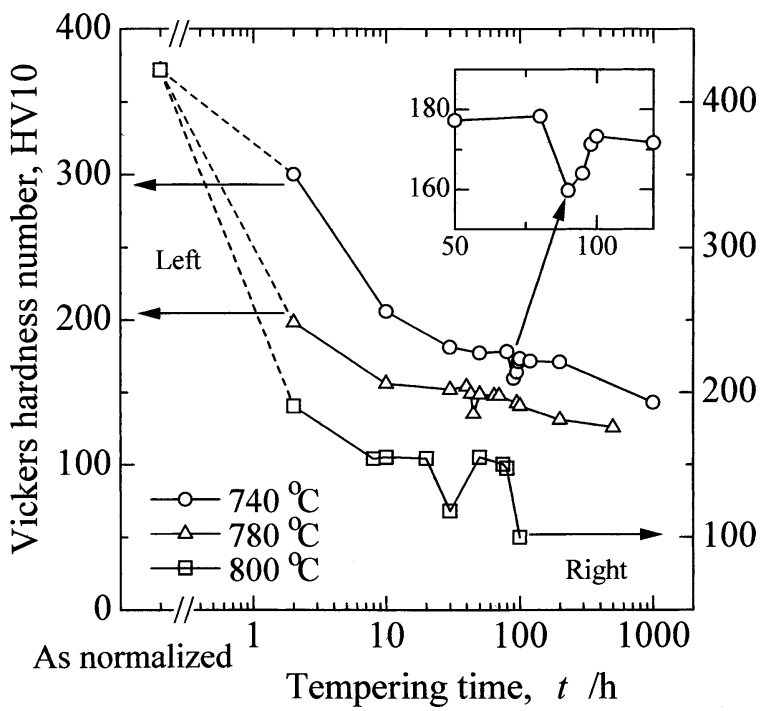

Fig. 2. Relation between Vickers hardness number and tempering time. 
decreased with increasing tempering time due to recovery. However, Fig. 3 shows clearly that the integral breadth temporarily increases near the peak time of the re-dissolution of $\mathrm{V}, t_{2}$. After the observation of the specimens tempered at 780 and $800^{\circ} \mathrm{C}$ was made, the repairs of an X-ray diffractmeter (XRD) were done and, therefore, some systematic differences may be included in the absolute values of integral breadth of the specimens tempered at $740^{\circ} \mathrm{C}$ as compared with those of 780 and $800^{\circ} \mathrm{C}$. However, the abnormal increase in the integral breadth was observed near $t_{2}$ independent of tempering temperature.

\subsection{Microstructure}

Microstructures of the tempered specimens at $780^{\circ} \mathrm{C}$ are shown in Fig. 4. Typical tempered martensitic structure is seen in the low magnification field. Both block and packet structures ${ }^{16)}$ cover all of the fields investigated for $2 \mathrm{~h}$-tempering and the high magnification view shows the areas where small precipitates are seen locally (Figs. 4(a) and 4(b)). Even after tempering for $45 \mathrm{~h}$, at this moment the re-dissolution of $\mathrm{V}$ actually begins at $780^{\circ} \mathrm{C}$, tempered martensitic structure seems to be stable in the low magnification field, but the high magnification view shows that the part of the block boundaries begins to become wavy (Figs. 4(c) and 4(d)). When tempering time is $100 \mathrm{~h}$, which corresponds to the peak of the re-dissolution, the block size looks like small in the low magnification field and tempered matensite structure becomes ambiguous (Fig. 4(e)). The high magnification view revealed that small precipitates are seen uniformly and the block boundaries become ambiguous and, therefore, new ferrite sub-grains are formed (Fig. 4(f)). When tempering time is $200 \mathrm{~h}$, the area where the block and packet like structures are not observed is clearly recognized even in the low magnification field (Figs. 4(g)

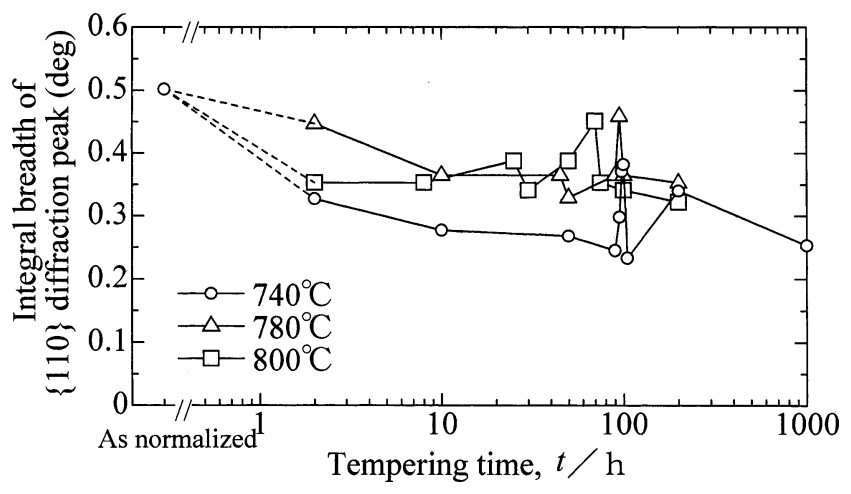

Fig. 3. Relation between integral breadth of $a\{110\}$ diffraction peak and tempering time.
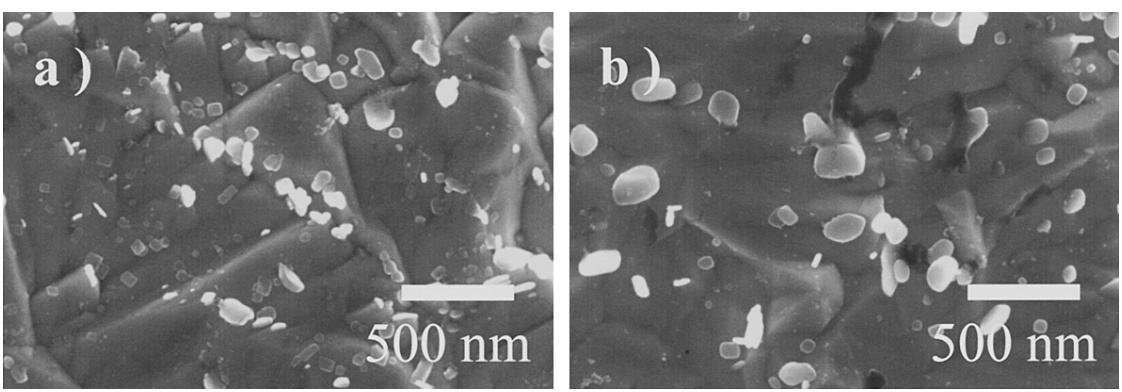

Fig. 5. FE-SEM images of the tempered specimens at $780^{\circ} \mathrm{C}$ for (a) $10 \mathrm{~h}$ and (b) $200 \mathrm{~h}$.

and 4(h))

Figures 5(a) and 5(b) show the scanning electron microscopy of the specimens, which were normalized and subsequently tempered at $780^{\circ} \mathrm{C}$ for 10 and $200 \mathrm{~h}$, respectively. The figures show that precipitates form lines with an interval of 0.5 to $1 \mu \mathrm{m}$, which may correspond with the width of block or the size of newly developed ferrite subgrains.

\subsection{Extracted Replica}

Figure 6 shows the FE-TEM images of the extraction replicas of the normalized and tempered states. The typical Debye ring patterns for the same field as shown in Fig. 6
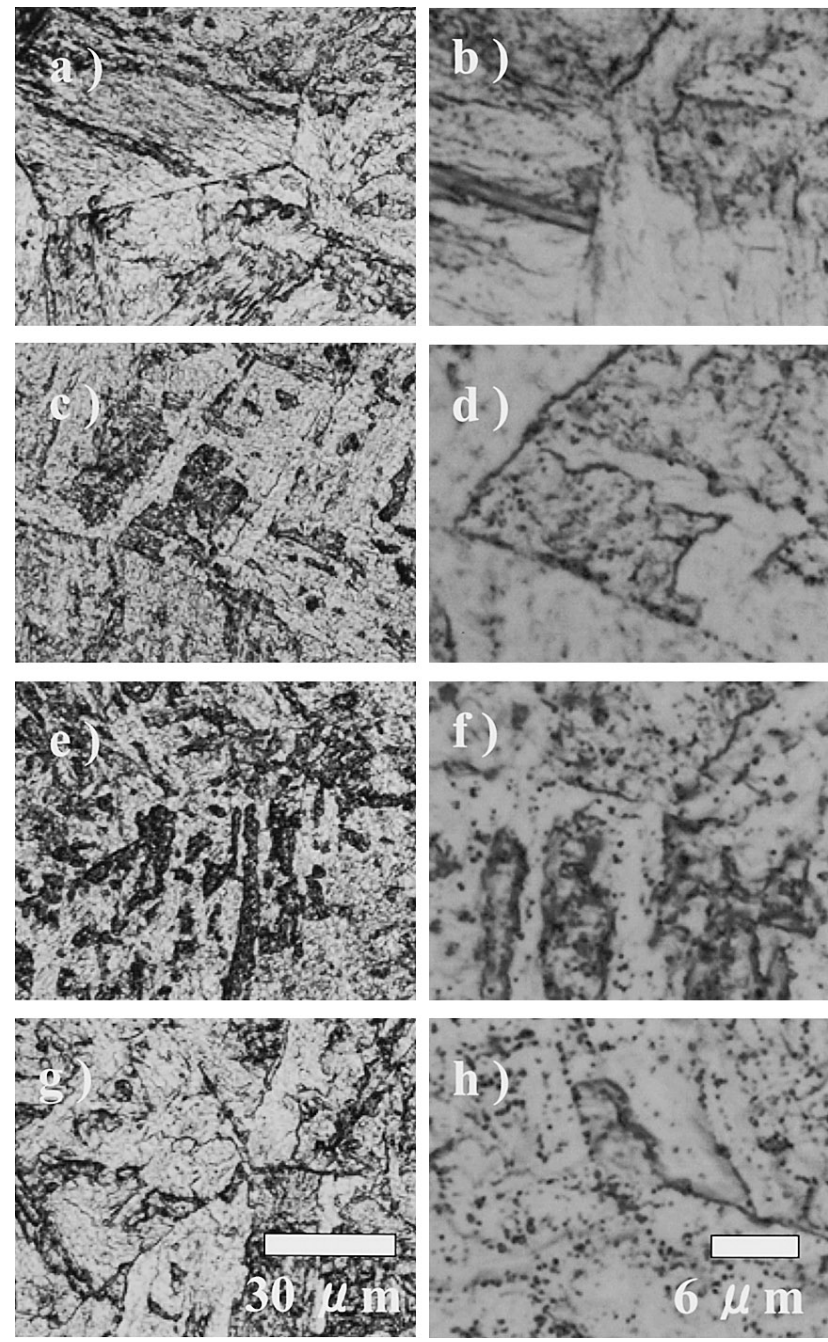

Fig. 4. Microstructures of the tempered specimens at $780^{\circ} \mathrm{C}$ for (a), (b) $2 \mathrm{~h}$; (c), (d) $45 \mathrm{~h}$; (e), (f) $100 \mathrm{~h}$; (g), (h) $200 \mathrm{~h}$. 

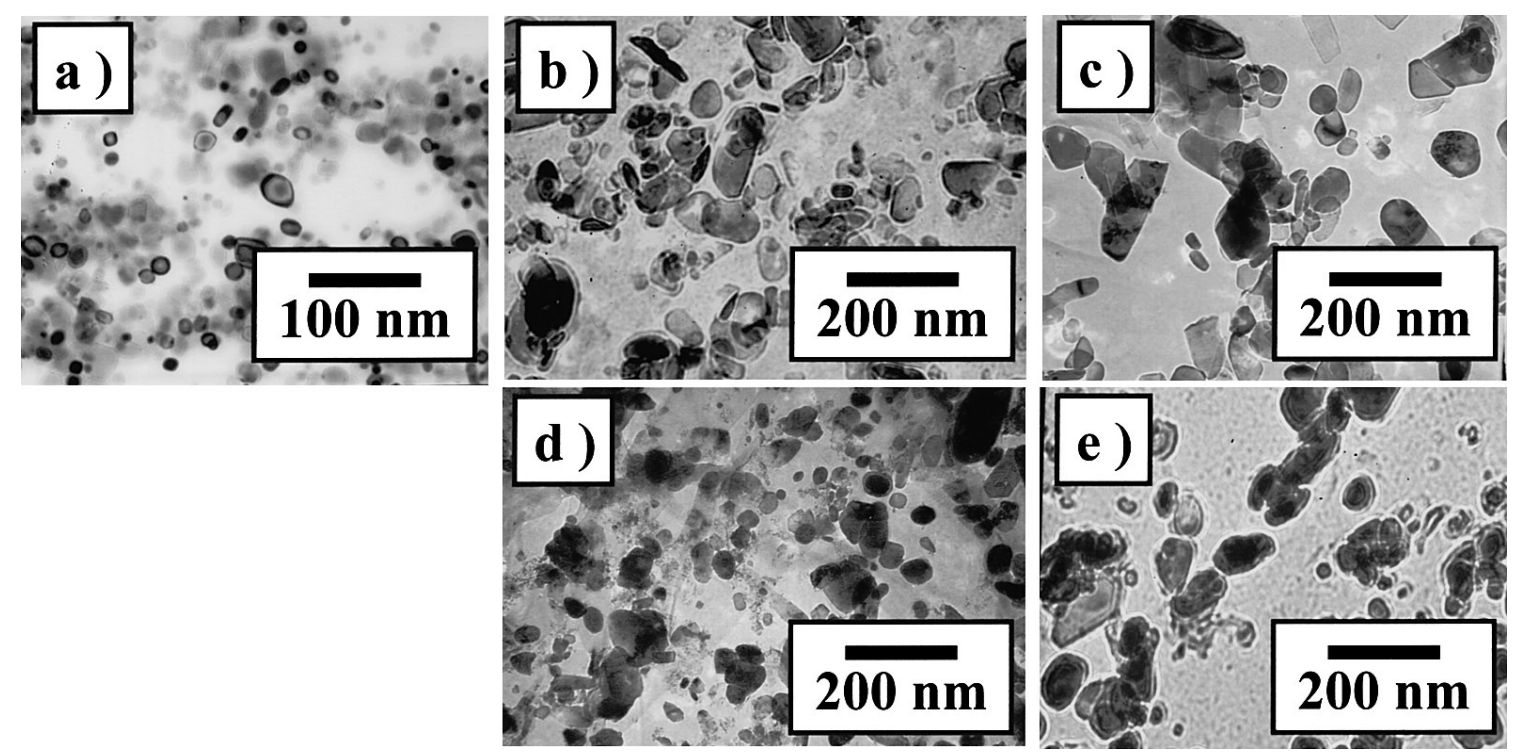

Fig. 6. FE-TEM images of the extracted replicas. (a) Normalized at $1050^{\circ} \mathrm{C}$ for $1 \mathrm{~h}$; (b)-(e) normalized at $1200^{\circ} \mathrm{C}$ for 1 $\mathrm{h}$ followed by tempering at $780^{\circ} \mathrm{C}$ for $10,45,90$ and $200 \mathrm{~h}$, respectively.
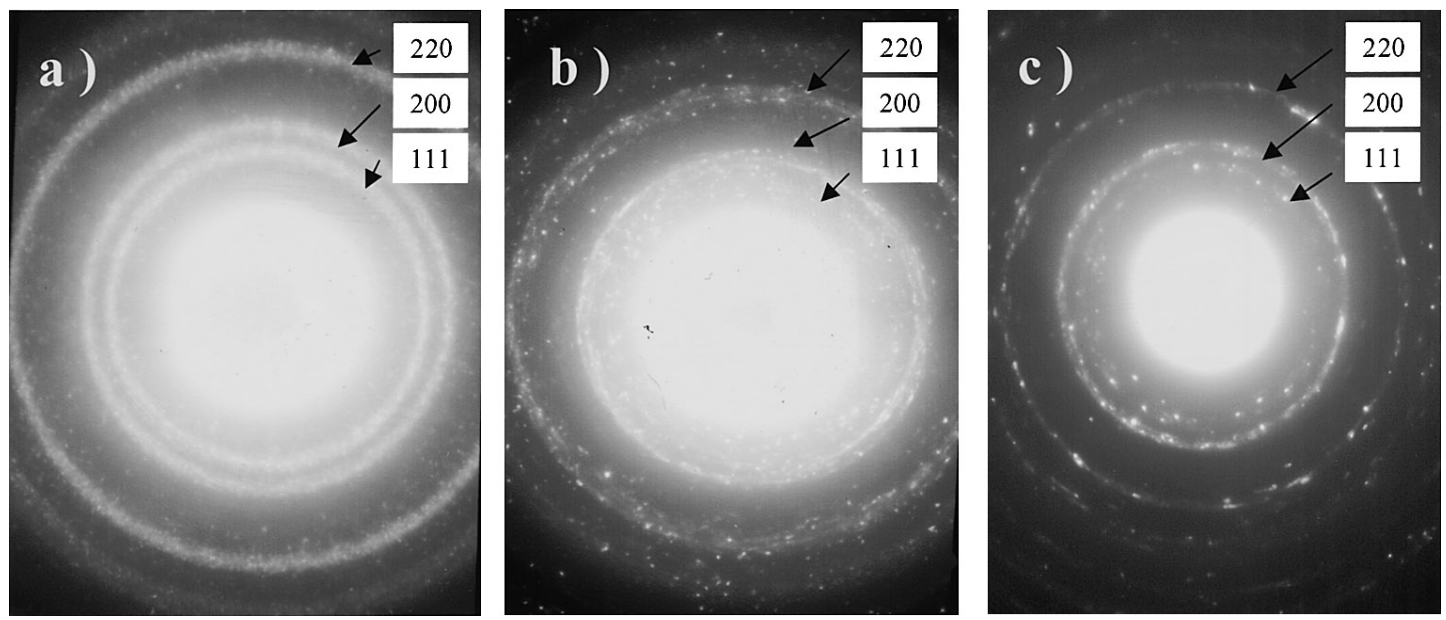

Fig. 7. Diffraction patterns of the extracted replicas. (a) Normalized at $1050^{\circ} \mathrm{C}$ for $1 \mathrm{~h}$; (b), (c) normalized at $1200^{\circ} \mathrm{C}$ for $1 \mathrm{~h}$ followed by tempering at $780^{\circ} \mathrm{C}$ for 45 and $200 \mathrm{~h}$, respectively.

are given in Fig. 7. Though the diffraction patterns for each precipitate are not shown, it is clear from Fig. 7 that the most of the precipitates have the crystal structure of $\mathrm{NaCl}$ type for both the normalized state and the tempered states. Namely, the steel examined precipitates only one kind of compound for both austenite and ferrite except for the miner precipitates, for example nonmetallic inclusions. Then, five precipitates are randomly selected for each specimen of the $1050^{\circ} \mathrm{C}$ normalized state and the $780^{\circ} \mathrm{C}$ tempered states for 45 and $200 \mathrm{~h}$ and the FE-TEM EDS analyses were made. The results are shown in Fig. 8. The figure shows that the major element contained in the precipitates is $\mathrm{V}$ for each case. However, a small amount of $\mathrm{Cr}$ and $\mathrm{Si}$ is observed in both the normalized state and the $45 \mathrm{~h}$-tempered state, i.e. before the peak of the re-dissolution of $\mathrm{V}$ and a small amount of Mo besides $\mathrm{Cr}$ and $\mathrm{Si}$ are also confirmed after the peak of the re-dissolution of V. Although it may be a technical problem that $\mathrm{Cr}$ and $\mathrm{Si}$ are detected in VN particles, Suzuki et al. ${ }^{17)}$ reported the similar results of EDS analysis on the extracted residues of high $\mathrm{Cr}$ heat

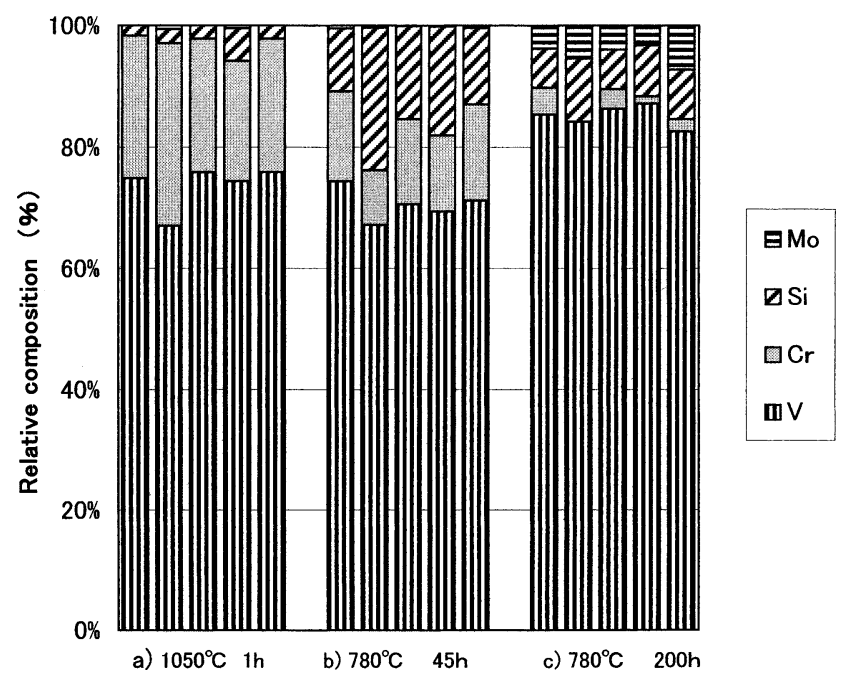

Fig. 8. The results of EDS analysis of the same specimen as Fig. 7. 
resistant steel, which is creep-ruptured at $650^{\circ} \mathrm{C}$, that $\mathrm{Nb}$, $\mathrm{Cr}$ and $\mathrm{Si}$ are detected in $\mathrm{V}(\mathrm{CN})$ particles.

Figure 6 shows that $\mathrm{VN}$ particles are rather small, i.e. about $20 \mathrm{~nm}$, when the specimen is normalized at $1050^{\circ} \mathrm{C}$ and $\mathrm{VN}$ particles are relatively large, i.e. about $20-100 \mathrm{~nm}$, when the specimen is normalized at $1200^{\circ} \mathrm{C}$ followed by tempering $780^{\circ} \mathrm{C}$. Namely, though the particle size in austenite is small, the particle size in ferrite is rather large independent of tempering time, i.e. before and after the peak of the re-dissolution of $\mathrm{V}$.

\section{Discussion}

\subsection{Re-dissolution of $\mathrm{VN}$}

Changes in the dissolved $\mathrm{V}$, the hardness number and the integral breadth are schematically shown in Fig. 9 in terms of these characteristic times, i.e. $t_{0}, t_{1}$ and $t_{2}$. Until $t_{0}$, the dissolved $\mathrm{V}$ and the hardness number decrease rapidly. The decrease in the dissolved $\mathrm{V}$ is caused by the precipitation of $\mathrm{VN}$, because in this experimental steel $\mathrm{VN}$ is the only major precipitate as mentioned above. The decrease in hardness is caused by the recovery of martensitic structure. Then, the decreases in the hardness and the dissolved $\mathrm{V}$ stop and the plateaus in the hardness and the dissolved $\mathrm{V}$ curves were observed up to $t_{1}$. Particles of $\mathrm{VN}$ are mainly precipitated on dislocations in $\mathrm{BCC}$ matrix ${ }^{18)}$ or small plate like particles of $\mathrm{VN}$ seem to have a strong interaction with dislocations. ${ }^{11)}$ Therefore, the plateaus observed between $t_{0}$ and $t_{1}$ may be caused by the pinning of dislocations by $\mathrm{VN}$ particles. A small depression in the hardness vs. time curve is observed near $t_{1}$. At that time the dissolved $\mathrm{V}$ begins to increase rapidly followed by the peak of the dissolved $\mathrm{V}$ at $t_{2}$. This increase in the dissolved $\mathrm{V}$ clearly indicates the redissolution of VN particles. Finally, the dissolved V seems to fall down continuing to an equilibrated value, while the

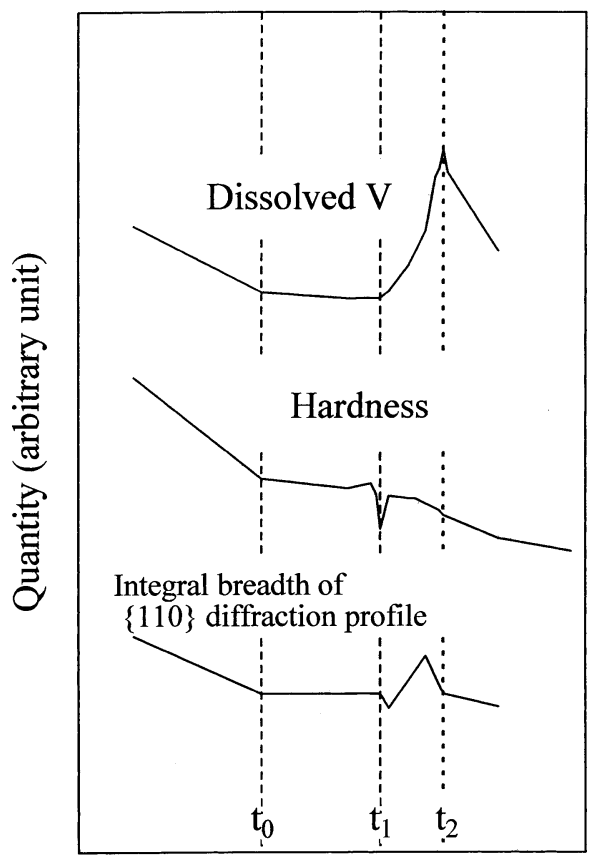

$\log$ (Tempering time) (arbitrary unit)

Fig. 9. Schematic diagram showing the relations between dissolved V, hardness, integral breadth and tempering time. hardness is decreasing due to a usual recovery process. According to Thermo Calc, ${ }^{19)}$ the equilibrated value of the dissolved $\mathrm{V}$ in ferrite is 0.04 and $0.047 \%$ at 800 and $740^{\circ} \mathrm{C}$, respectively. Therefore, since the lowest value of the dissolved $\mathrm{V}$ in the plateaus is near $0.15 \%$, the precipitation of $\mathrm{VN}$ should be continued further.

The changes in the integral breadth as shown in Fig. 3 are rather complex. However, the integral breadth decreases gradually with increasing tempering time up to $t_{1}$ and, then, decreases rapidly in a small range. After that the peak of the integral breadth is observed just before $t_{2}$. Finally, the integral breadth tends to decrease with increasing tempering time. The decrease in the integral breadth with increase in tempering time can be explained in terms of recovery. However, the sharp increase in the integral breadth near $t_{2}$ should indicate that some defects in an X-ray crystallographic scale are newly introduced accompanying with the re-dissolution of $\mathrm{VN}$ particles.

Though the detailed discussion on the origin of the depression in hardness and the abnormal increases in the integral breadth should be needed, it is clear from Figs. 1, 6 and 7 that $\mathrm{VN}$ particles begin to re-dissolve at a time of $t_{1}$. At this time lath matensite and/or block of lath structure are recognized to begin to partially decompose in the high magnification optical microscopic views, though the obvious change in the low magnification field is not confirmed (Fig. 4).

Any way, the characteristic times, $t_{0}, t_{1}$ and $t_{2}$, are dependent on temperature. Therefore, inverse time is plotted as a function of inverse absolute tempering temperature (Fig. 10). The apparent activation energies, $Q_{0}, Q_{1}$ and $Q_{2}$, for $t_{0}$, $t_{1}$ and $t_{2}$, respectively, are calculated as 178,164 and $40 \mathrm{~kJ} / \mathrm{mol}$, while the activation energies for lattice diffusion, boundary diffusion of $\alpha$-Fe and the activation energy of $\mathrm{N}$ in $\alpha$-Fe are 241,189 and $77 \mathrm{~kJ} / \mathrm{mol}$, respectively. ${ }^{20)}$ The phenomena observed are not caused by a simple diffusion process, but the above analyses suggest that the phenomena corresponding to $t_{0}$ and $t_{1}$ are controlled by the defect assisted diffusion of the substitutional elements in the matrix and the peak of the re-dissolution of $\mathrm{VN}$ is controlled by the diffusion of interstitial element, $\mathrm{N}$, in the $\mathrm{BCC}$ matrix, respectively.

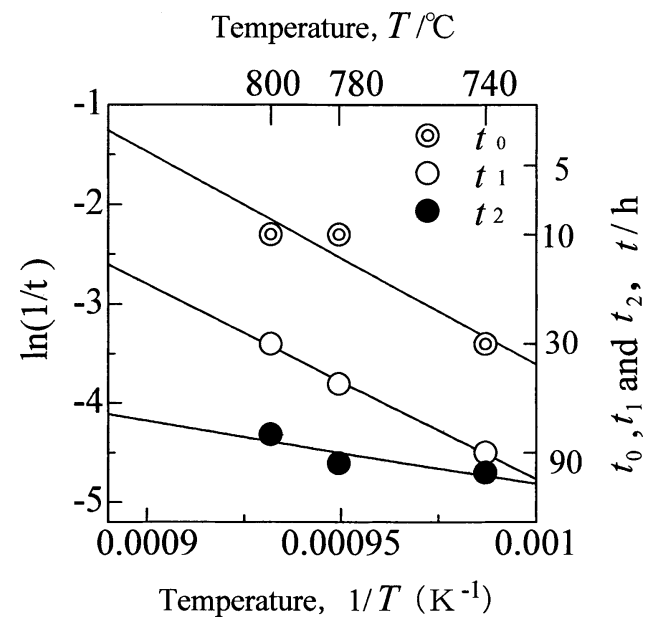

Fig. 10. Arrhenius plot of the characteristic times, $t_{0}, t_{1}$ and $t_{2}$. 


\subsection{Precipitation Behavior of the Nb-C System}

In the previous work ${ }^{9)}$ it has been reported that the re-dissolution of $\mathrm{NbC}$ has been found when the specimen is normalized at $950^{\circ} \mathrm{C}$ followed by tempering at $800^{\circ} \mathrm{C}$ for $2 \mathrm{~h}$, i.e. a practical tempering time. Namely, $\mathrm{NbC}$ particles precipitated in austenite have re-dissolved in a practical tempering process. On the other hand, in $\mathrm{Fe}-\mathrm{Cr}-\mathrm{V}-\mathrm{N}$ system we cannot find out the condition of re-dissolution of $\mathrm{VN}$ by the similar heat treatment. Therefore, in this alloy system we have made a systematical tempering study and found the sequential process of the precipitation of $\mathrm{VN}$ particles through isothermal tempering, which is the quasi-steady state of the precipitation (plateau), the subsequent re-dissolution and finally the precipitation. Therefore, we have tried to confirm the same phenomenon should occur in an $\mathrm{Fe}-\mathrm{Cr}-\mathrm{Nb}-\mathrm{C}$ system. The chemical composition is $0.136 \% \mathrm{C}-0.3 \% \mathrm{Si}-0.37 \% \mathrm{Mn}-0.011 \% \mathrm{P}-0.0005 \% \mathrm{~S}-$ $8.58 \% \mathrm{Cr}-0.95 \% \mathrm{Mo}-0.177 \% \mathrm{~V}-0.085 \% \mathrm{Nb}-0.0007 \% \mathrm{~N}$ and the balance is Fe. The preparation method of the material is given in the previous paper ${ }^{9)}$ and the experimental method is similar with those mentioned in Sec. 2.

The dissolved $\mathrm{Nb}$ in BCC matrix is measured and the results are shown in Fig. 11. Figure 11 is interpreted in the same way as in the case of VN: firstly NbC particles precipitate and subsequently re-dissolve into the matrix followed by the final re-precipitation. Figure 12 shows the change in hardness with tempering time. In this alloy system the depression in hardness is also clearly observed near the beginning of the re-dissolution of $\mathrm{NbC}$, though the long time plateau in a hardness $v s$. tempering time curve as shown in Fig. 2 is not observed. Figure 13 shows the change in integral breadth of a $\{110\}$ X-ray diffraction peak. The integral breadth decreases with increasing tempering time, but the figure shows a small peak at about $2 \mathrm{~h}$ in the integral breadth curve. Figure 14 shows microstructures tempered at $800^{\circ} \mathrm{C}$. Partial decomposition of the blocks of lath martensite is clearly observed at $2.5 \mathrm{~h}$ tempering, when the re-dissolution of $\mathrm{Nb}$ is beginning. After that, the martensite is fully tempered or the boundaries of the newly developed ferrite sub-grains are decorated with fine MX type precipitates.

The above observation shows that $\mathrm{Nb}$ is separated from the matrix as $\mathrm{NbC}$ firstly and the precipitated $\mathrm{NbC}$ particles begin to re-dissolve by tempering at $800^{\circ} \mathrm{C}$ for $1.5 \mathrm{~h}$ and the

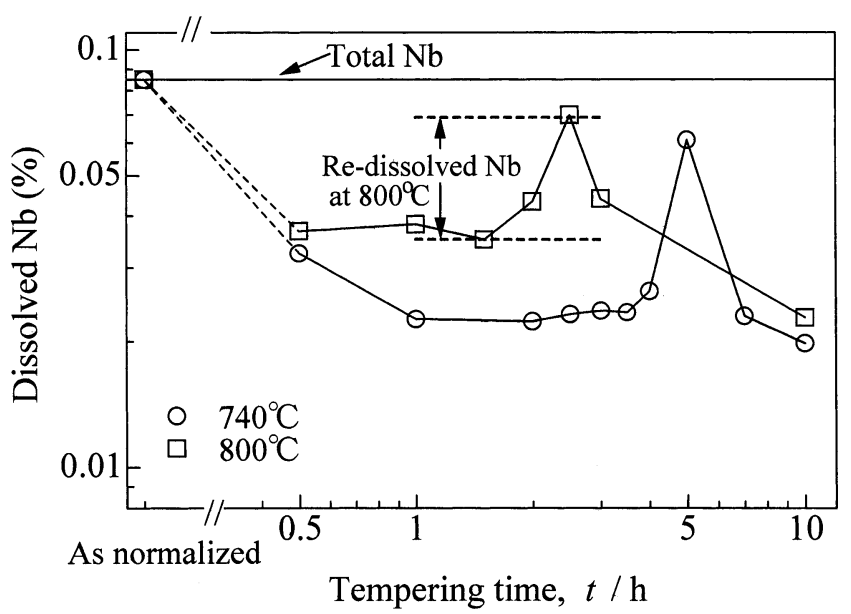

Fig. 11. Relation between dissolved $\mathrm{Nb}$ and tempering time. re-dissolution of $\mathrm{NbC}$ reaches to the peak at $2.5 \mathrm{~h}$. The small hardness depression, the small integral breadth peak and the beginning of the decomposition of the blocks of lath martensite are accompanied by the re-dissolution of $\mathrm{NbC}$ particles. The apparent activation energies for the beginning of the re-dissolution of $\mathrm{Nb}, Q_{1}$, and for the peak

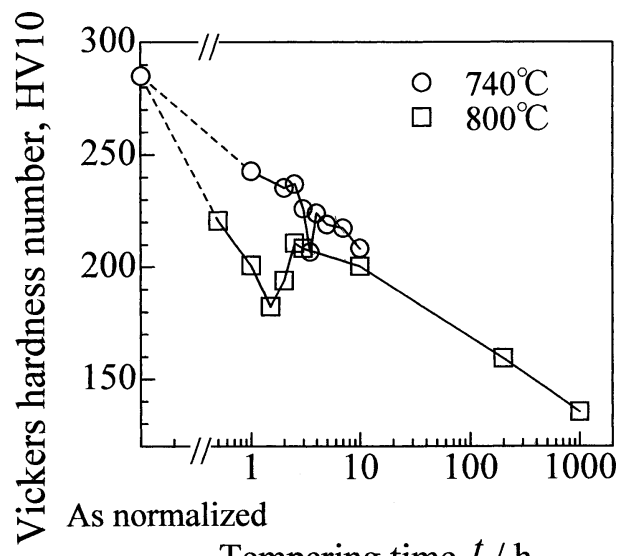

Tempering time, ${ }^{t} / \mathrm{h}$

Fig. 12. Relation between Vickers hardness and tempering time of $9 \% \mathrm{Cr}-1 \% \mathrm{Mo}-0.09 \% \mathrm{Nb}$ steel.

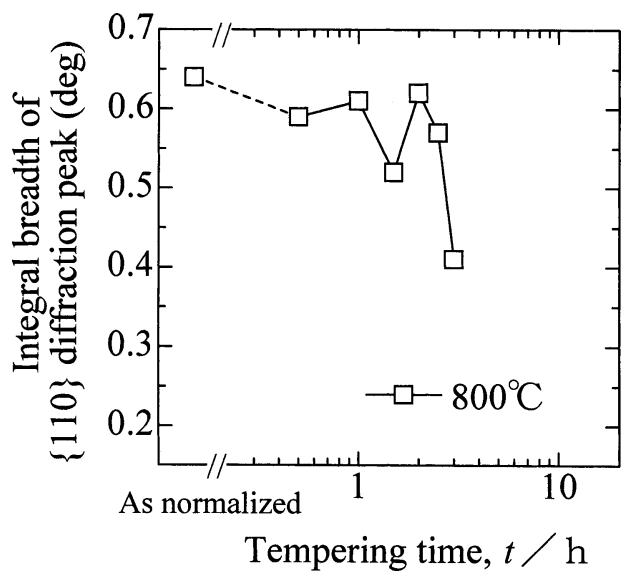

Fig. 13. Relation between integral breadth and tempering time of $9 \% \mathrm{Cr}-1 \% \mathrm{Mo}-0.09 \% \mathrm{Nb}$ steel.
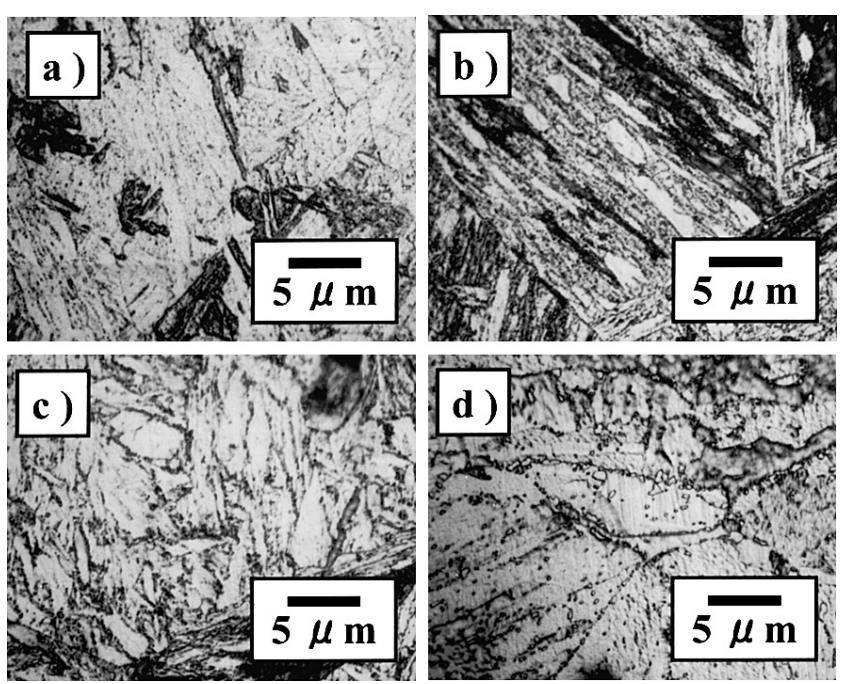

Fig. 14. Microstructures of $9 \% \mathrm{Cr}-1 \% \mathrm{Mo}-0.09 \% \mathrm{Nb}$ steel tempered at $800^{\circ} \mathrm{C}$ for (a) $1 \mathrm{~h}$, (b) $1.5 \mathrm{~h}$, (c) $2.5 \mathrm{~h}$ and (d) $200 \mathrm{~h}$ 
re-dissolution of $\mathrm{Nb}, Q_{2}$, are calculated as 128 and $104 \mathrm{~kJ} / \mathrm{mol}$. The activation energies of lattice diffusion and boundary diffusion of $\mathrm{Fe}$ are 241 and $189 \mathrm{~kJ} / \mathrm{mol}$, respectively ${ }^{20)}$ and the activation energy of $\mathrm{C}$ in $\alpha$-Fe is $81 \mathrm{~kJ} / \mathrm{mol}^{20)}$ The phenomena observed are not caused by a unique diffusion process, but the above analyses suggest that the phenomenon corresponding to $t_{1}$ is controlled by the defect assisted diffusion of the substitutional elements in the matrix and the peak of the re-dissolution of $\mathrm{Nb}$ is controlled by the diffusion of $\mathrm{C}$ in the matrix, respectively.

The above experimental results and related discussions are quite similar with the observation in the $\mathrm{Fe}-\mathrm{Cr}-\mathrm{V}-\mathrm{N}$ system as mentioned in Sec. 3.

From both the above observation and the conclusions of Sec. 4.1 it is found that the re-dissolution of the MX type particles should have been observed when the martensite structure is decomposed and ferritic sub-grains are formed in the similar alloy systems containing MX particles. However, Kadoya ${ }^{21)}$ studied precisely the precipitation behavior of $9 \mathrm{Cr} 1 \mathrm{Mo} 0.2 \mathrm{~V} 0.08 \mathrm{Nb}$ steel of the normalized and tempered state and reported that the amount of the MX type carbide is roughly constant from the early stage of aging at $650^{\circ} \mathrm{C}$ up to about $50000 \mathrm{~h}$, though recovery should have occurred. There are many reports on the precipitation behavior of the MX type particles, however, the re-dissolving of the MX type particles has not been reported except for our previous work. ${ }^{9)}$ In many practical heat resistant steels a large amount of $\mathrm{M}_{23} \mathrm{C}_{6}$ carbide and Laves phase are precipitated besides a very small amount of MX type carbo-nitride, which depends on tempering temperature and time. This suggests that the small change in the metallic constituent element of MX should be masked by the large changes of the metallic element of $\mathrm{M}_{23} \mathrm{C}_{6}$ and Laves phase. In this alloy system $\mathrm{M}_{23} \mathrm{C}_{6}$ carbide is also precipitated at the tempering temperature adopted. However, we have measured directly the dissolved $\mathrm{Nb}$ in the matrix and $\mathrm{Nb}$ is believed to have little solubility in $\mathrm{M}_{23} \mathrm{C}_{6}$ type carbide ${ }^{18)}$ and, therefore, the large amount of $\mathrm{M}_{23} \mathrm{C}_{6}$ precipitates should not affect the detection of $\mathrm{Nb}$ in the matrix.

\subsection{Explanation of the Re-dissolution of MX Type Particles}

In the previous sections the evidences for the temporal re-dissolution of $\mathrm{VN}$ or $\mathrm{NbC}$ particles, which are both the equilibrated phases in BCC matrix, have been shown. This phenomenon was initially found essentially in the practical normalizing and subsequent tempering process of $\mathrm{Fe}-\mathrm{Cr}-$ $\mathrm{Nb}-\mathrm{C}$ system, ${ }^{12)}$ but we have revealed that the precipitation, the succeeding re-dissolution and the final re-precipitation of MX type particles sequentially occur during a simple isothermal tempering process of high $\mathrm{Cr}$ martensitic steel.

At an early stage of the phenomenon the plateaus were observed in a time vs. dissolved $\mathrm{V}$ or $\mathrm{Nb}$ diagram (Figs. 1 and 11). During this stage dislocations are pinned by the precipitated MX type particles and the further recovery due to tempering is apparently delayed. This means that the microstructure reaches a quasi-equilibrated state. Therefore, a trigger should be needed for the break down of the quasiequilibrated state. Figure 15 illustrates one of the possible triggers for the break down of the quasi-equilibrated state.

Immediately after normalization many dislocations are

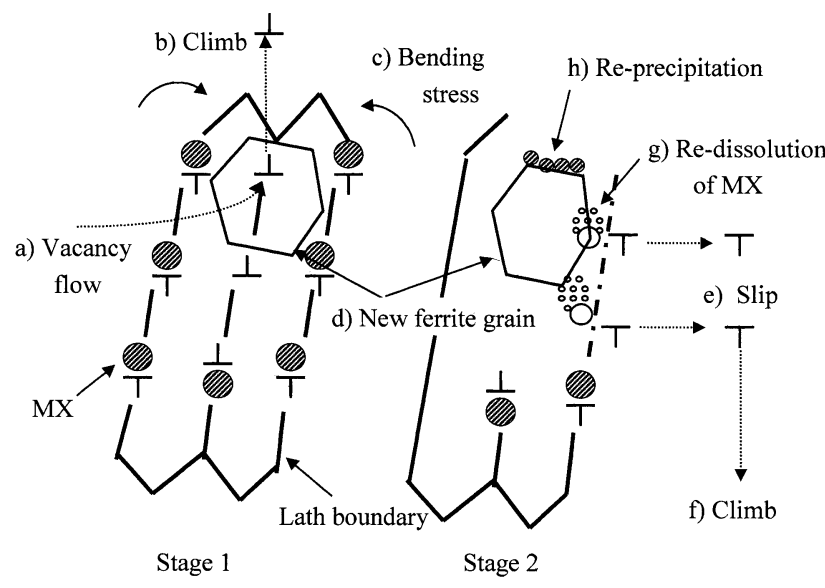

Fig. 15. Schematic diagram illustrates a possible mechanism for the re-dissolution of MX particles. Stage 1 shows the generation of a small perfect crystal and a pair of bending stress due to a local vacancy flow and Stage 2 shows slip motions caused by the generated local stress the redissolution of MX and the re-precipitation of MX. Processes (a) through (h) occur sequentially.

present in the matrix, and thus MX type particles should precipitate on the dislocations by tempering because of the strong interaction between them. If there is enough number of precipitates, the dislocations were pinned tightly and, therefore, the recovery stops for a while. However, since the precipitates do not decorate all segments of the dislocations and dislocations are essentially thermally unstable, the dislocations, which are not locked tightly, should climb and be annihilated. Figure 15 (Stage 1) illustrates how the dislocations are annihilated and a small perfect crystal and local stress are generated. Most of dislocations in lath or block boundaries are locked by MX particles, but some segments of the dislocations do not locked. Excess vacancy flow, which exists locally, leads to climbing of the unlocked segments of the dislocations and the climbing dislocations are annihilated elsewhere.

The local annihilation of the dislocations causes the decomposition of lath martensite into an unstrained small perfect crystal zone. This corresponds to the so called effective particle size, which is usually used in the field of X-ray diffraction study. ${ }^{14)}$ The decomposition of the heavily strained martensite itself should reduce the integral breadth, but newly formed very fine effective particle size may increase in the integral breadth, and in total the integral breadth may increase at this moment as shown in Figs. 3, 9 and 13. At the same time, the climbing generates a pair of additive bending stresses in the direction of disappearing the flow-in vacancies as shown in the Fig. 15 (Stage 1). This causes bending of lath structure or block, which subsequently induces the local stress around the small perfect crystal zone. This local stress should unlock the dislocations by slip from MX type particles which are around the perfect crystal as shown in Fig. 15 (Stage 2). The resultant free dislocations may be annihilated elsewhere, which causes the bending of lath structure again. These chain reactions induce the isolated MX type particles and the decrease in dislocation density. The isolated MX type particles are energetically unstable, because the isolation increases the free energy by the release of the interaction energy, which should be always 
negative, if an MX particle precipitates on a dislocation, and the re-dissolution of MX type particles may occur when the interaction is strong and the particle is small enough for re-dissolution. As a consequence, the local annihilation of dislocations may take place, which causes the decomposition of blocks of lath martensite and forms the ferrite sub-grains. The annihilation of dislocations and the resultant re-dissolution of MX type particles may cause the temporarily softening observed in Figs. 2 and 12.

Therefore, local internal stress caused by the local recovery and the chain reactions may induce unpinning of the dislocations locked by the MX type particles, which possibly causes the dissolution of the MX type particles. However, the re-dissolved metallic elements, such as $\mathrm{V}$ or $\mathrm{Nb}$, suddenly form MX type particles again on some nucleation sites. In these consideration, the annihilation of dislocations always needs the movement of the matrix elements and, therefore, $t_{0}$ and $t_{1}$ are both controlled by diffusion of Fe or substitutional elements, but there are many dislocations so that they assist the diffusion of the matrix elements and, therefore, the activation energy for this processes are about half of the self diffusion as shown in Fig. 10. On the other hand, the dissolving process is possible only by the movement of the interstitials and thus the dissolving rate, $t_{2}$, is always controlled by the diffusion rate of interstitial elements, such as $\mathrm{N}$ or $\mathrm{C}$ as shown in Fig. 10.

It is difficult to obtain a direct evidence for the proposed mechanism. However, the mechanism is experimentally supported by the following results. Just before the peak of the re-dissolution of MX particles temporal softening (Figs. 2 and 12) and sharp increase in the integral breadth (Figs. 3 and 13) are observed, which indicate decrease in the number of dislocations and/or precipitates and generation of small ferrite grains and/or local internal stress around them, respectively. At the peak time of the re-dissolution most of the tempered martensite is decomposed (Figs. 4 and 14).

Figure 8 shows that the chemical compositions of $\mathrm{VN}$ before and after the peak of the re-dissolution little differ each other. This figure shows that since the MX type particles before the peak contains higher $\mathrm{Cr}$ than that of after the peak, the particles should squeeze $\mathrm{Cr}$ in accordance with the proceeding of the tempering time. This squeezing can be one of the triggers for the re-dissolution of MX type particles. The change in free energy before and after the compositional change of the MX type particles depends on the energy change through the formation of MX phase in the matrix, interaction energy with dislocation and the interface energy. ${ }^{22)}$ Therefore, the precise simulation should be needed for the re-dissolution of the MX type particles. However, if the compositional change of the same MX phase is the driving force for a trigger to the re-dissolution, the reason for the rapid change in the re-dissolution as shown in Figs. 1 and 11 should be explained. However, there is no evidence for the inevitability for the sudden change in composition of MX type particles.

Growing of MX type particles during tempering needs the supply of the constituent elements of MX type particles. When the state is quasi-equilibrated, precipitates with small size should dissolve into the matrix, which causes the coarsening of the large particles. Finally the inter-particle distance may increase, which may weaken the pinning effect of dislocations. And therefore, the annihilation of the weakly pinned dislocations may take place with the aid of some local stresses. This sequence also provides the redissolution of the constituent element into the matrix. However, this process is a usual process for the coarsening of precipitates and the process should take place gradually and does not need the sudden change in metallurgical variables as shown in Figs. 1-3, 11-13. Also the size of the MX type particles before the peak is as the same size that after the peak shown in Fig. 6. Therefore, an idea that the coarsening of the MX type particles is a trigger of the dissolution of MX is doubtful. Any way, an idea other than that of Fig. 15 may be possible, however the re-dissolution of the MX type particles is accompanied by the decomposition of the lath martensitic structure. Therefore, the idea shown in Fig. 15 is reasonable for the trigger of the re-dissolution of MX type particles.

\section{Conclusions}

Precipitation behavior of $\mathrm{VN}$ in high $\mathrm{Cr}$ martensitic heat resistant steel during isothermal tempering has been studied. Dissolved $\mathrm{V}$ in the matrix, hardness and integral breadth of $\{110\}$ X-ray diffraction peak are examined and optical microscope, transmission electron microscope and scanning electron microscope are also used for analyzing the precipitation behavior: following conclusions are obtained.

(1) During isothermal tempering at $740-800^{\circ} \mathrm{C}$ of $7 \% \mathrm{Cr}-0.4 \% \mathrm{~V}-0.09 \% \mathrm{~N}$ steel, a following sequential precipitation process takes place: particles of VN precipitate on dislocations in the early stage of tempering and, then, after a quasi-steady period the precipitated VN particles temporarily re-dissolve and finally $\mathrm{VN}$ particles re-precipitate again.

(2) Around a peak time of the re-dissolution of $\mathrm{VN}$, temporal decrease in hardness and temporal increase in the integral breadth of a $\{110\}$ X-ray diffraction peak take place. After the peak of the re-dissolution of $\mathrm{VN}$, fine $\mathrm{VN}$ particles re-precipitate within ferrite sub-grains and on the sub-grain boundaries.

(3) The similar phenomenon is experimentally confirmed on $0.14 \% \mathrm{C}-9 \% \mathrm{Cr}-1 \% \mathrm{Mo}-0.2 \% \mathrm{~V}-0.09 \% \mathrm{Nb}$ steel, which precipitates $\mathrm{NbC}$.

(4) The mechanism of the re-dissolution of MX type particles is as follows:

i) Initially, the annihilation of dislocations and the precipitation of MX type particles on dislocations are progressing in parallel.

ii) Then, the pinning of dislocations by the MX type precipitates becomes saturating and the quasi-equilibrated state is kept for a while.

iii) Some triggers, for example local climbing of dislocations, generate local stress, which induces unlocking of the pinned dislocations. The resultant isolated MX type particles become thermodynamically unstable, which cause the re-dissolving of the MX type particles.

iv) During the re-dissolution of MX, well tempered lath martensitic structure is transformed into ferritic subgrains. Finally, MX type particles are re-precipitated 
within the sub-grains and on sub-grains boundaries.

v) The generation of new ferrite grains causes the new local stress around the grains, which induces unlocking the pinned dislocations. These chain reactions bring about the sharp peak of the re-dissolution of MX particles.

\section{Acknowledgements}

The authors are deeply thanking Dr. T. Nishimura of NKK Co. for supplying the experimental steels. Mr. T. Tanaka of Nissei Science Co. is thanked for the arrangement of the usage of FE-SEM. Also, the authors thank SUZUKI foundation for supporting a part of this study.

\section{REFERENCES}

1) V. K. Sikka, C. T. Ward, and K. C. Thomas: Ferritic Steels for HighTemperature Applications, ed. by A. K. Khare, ASM, Metals Park, $\mathrm{OH},(1983), 65$.

2) F. Masuyama: ISIJ Int., 41 (2001), 612.

3) S. J. Sanderson: Ferritic Steels for High-Temperature Applications, ed. by A. K. Khare, ASM, Metals Park, OH, (1983), 85.

4) Y. Kadoya and E. Shimizu: Tetsu-to-Hagané, 86 (2000), 189.

5) M. Tamura, H. Sakasegawa, Y. Kato, A. Kohyama, H. Esaka and K. Shinozuka: J. Nucl. Mater., 321 (2003), 288.
6) I. Kozasu: Materials Science and Technology, ed. by F. B. Pickering, VCHmbH Weinheim, (1992), 183.

7) F. B. Pickering: Materials Science and Technology, ed. by F. B. Pickering, VCHmbH, Weinheim, (1992), 335.

8) H. Kobayashi and Y. Kasamatu: Tetsu-to-Hagané, 67 (1981), 1990.

9) M. Tamura, K. Ikeda, H. Esaka and K. Shinozuka: ISIJ Int., 41 (2001), 908

10) K. Yamada, M. Igarashi, S. Muneki and F. Abe: ISIJ Int., 41 (2001), Supple., S116.

11) K. Miyata, Y. Sawaragi, H. Okada, F. Masuyama, T. Yokoyama and N. Komai: ISIJ Int., 40 (2000), 1156.

12) M. Tamura, K. Shinozuka, H. Esaka, S. Sugimoto, K. Ishizawa and K. Masamura: J. Nucl. Mater, 283-287 (2000), 667.

13) M. Tamura, H. Iida, H. Esaka and K. Shinozuka: ISIJ Int., accepted.

14) A. R. Stokes and A. J. C. Wilson: Proc. Phys. Soc., 56 (1944), 174

15) G. K. Williamson and W. H. Hall: Acta Metall., 1 (1953), 22.

16) S. Morito and T. Maki: Materia Jpn., 40 (2001), 629.

17) K. Suzuki, S. Kumai, H. Kushima, K. Kimura and F. Abe: Tetsu-toHagané, 89 (2003), 691.

18) N. K. Balliger and R. W. K. Honeycombe: Met. Sci., 14 (1980), 121.

19) B. Sundman, B. Jansson and J.-O. Andersson: Calphad, 9 (1985), 153.

20) Handbook of Iron and Steel, Vol. 3, 3rd ed., ed. by ISIJ, Maruzen, Tokyo, (1981), 349.

21) Y. Kadoya B. F. Dyson and M. McLean: Metall. Mater. Trans. A, 33A (2002), 2549.

22) Å. Gustafson and J. Ågren: Acta Mater, 46 (1998), 81. 